\section{PHYSTOLOGICAL OBSERVATIONS UPON DR. HARLEY'S "AUTO-CLINICAL REMARKS."}

By HENRY POWER, M.B., F.R.C.S., OPHTHALMYO SURGEON TO ST. GHORGE's HOSPITAL.

THe short report of Dr. Harley's case, published in the columns of Tre LANCET last week, under the title of "AutoClinical Remarks," is one of great interest, not only pathologically as an instance of a rare form of disease, and therapeutically as indicating the value of rest in the treatment of retinal affections, but also physiologically in reference to the singular phenomena observed. Whilst making a few comments upon the report, I may be permitted to offer my congratulations, in common with many others of the profession, to Dr. Harley on the restoration of his sight, and to trust that his recovery may be permanent. His symptoms appear to have been due to a condition of hyperæmia (sufficiently attested by the rupture of one or more of the vessels), occasioning an extraordinary exaltation of the sensibility of the retina, but not accompanied by what must be regarded as the essential feature of inflammation--interstitial effusion. At all events, when inflammation is really present, hyperæesthesia and extreme intolerance of light are not in general prominent symp toms. Looking at the case from a purely physiological point of view, the three effects noticed-of abolition of the powers of distinguishing colours, of appreciating distance, and the greater persistence than usual of images on the retina-are all instructive. That long retention in darkness abolishes the power of distinguishing colours is interesting, not only as proving that the more refrangible rays of light produced by more rapid undulations are really the most powerful excitors of the retina-greys, reds, and browns giving the sensation of blackness, or the negation of colour, - but also as furnishing another instance of similar effects being producible by opposite causes, the same phenomena being observed, though not in quite so marked a degree, in the healthy eye by short exposure to excess of light, as by looking at the sun for a few moments, or even at the glare of the electric light. In both cases the results are the same, though in one occurring in a retina the sensibility of which has been modified by prolonged rest, and in the other by over-stimulation.

The extreme elongation or extension of all objects noticed by Dr. Harley is a phenomenon of not very unfrequent occurrence after the application of Calabar bean to the eyes, and the term macropsy lias been applied to it. The opposite condition (micropsy) - all things looking smaller than natural-is occasionally seen after the instillation of atropine. It is not easy to offer an explanation of these effects. Two conditions which were also probably present in Dr. Harley's case are common to both-namely, the loss of the power of accommodation, and immobility of the iris. It has occurred to me that the great extension noticed after the Calabar bean and ky Dr. Harley might possibly be explained by, or rather be connected with, diminished sensibility of the retina for the lower tints of colour; for as we judge of distance very much by play of light and shade, and as objects in proportion to their remoteness appear of duller tints and less defined, so the retina in his case, taking less cognisance than nsual of more distant or more feebly illaminated objects, led the mind to refer them to a more remote position than they actually occupied, thus giving the impression of elongation. Or it might otherwise be explained on the supposition that the retina, become highly sensitive by pro. longed rest, perceived innumerable gradations of light and shade in every object which usually pass unnoticed, but which here filled the mind, and gave the impression of space, just as the apparent field of vision is in every eye increased in proportion to the number of objects seen in it.

In regard to the great persistence of impressions made on the retina during Dr. Harley's recovery, I may remark that I have observed the retina is much more retentive of the images of external objects in the morning, especially soon after waking, than at night.

Those who are engaged in the practice of ophthalmic surgery will be interested to receive further details of Dr. Harley's case, and to know what means were adopted to obtain "total darkness."

Seymour-street, W., Feb. 1868.
ON A CASE OF

\section{EXCISION OF, AND AMPUTATION AT, THE HIP _ JOINT ; RECOVERY.}

BY J. H. BARNES, EsQ., M.R.C.S., SURGEON TO THE LIVERPOOU, WORKHOUSIG INFIRMARY.

JoHx $M \cdot K-$, aged eleven years, two or three weeks previous to his removal to hospital on the 6th of July, 1867, was in the street on his hands and knees, when another boy jumped suddenly on his back, causing "his right leg to give way under him, and producing an acute pain in his hip." For a few days he was able to limp about his room; but the pain increasing, and the leg commencing to swell, he was obliged to keep his bed.

On admission into hospital, there was found to be great swelling and enlargement of the limb from the hip to the knee. The thigh was adducted and rotated over that of the sound side, on which he constantly lay; and any effort to change the position of the injured limb, or examine it minutely, gave rise to such suffering that it was not persisted in. He was, therefore, placed on a diet suited to his weak and depressed state, and the hip and thigh enveloped in poultices. Fluctuation becoming in a fow days more pronounced, an incision was made on the inner aspect of the thigh, just above the knee, this being (in the position in which he kept his leg) the most depending point. From this opening pus was freely discharged, and the swelling at the hip daily diminishing, a more satis factory examination of it became possible. Fracture of the neck of the femur, with dislocation of the head on the dorsum ilii, was diagnosed; and as the patient, in spite of everything that could be done to keep him up, was rapidly getting weaker, being so emaciated that his forearms were bi-concave and translucent, I resolved on at once excising the hip-joint.

The patient, on the 15th of August, having been carried into the operating-room and placed under the influence of chloroform, I made a horseshoe incision down to the joint, commencing at a point posterior to the great trochanter, and terminating it at a corresponding point anteriorly. On clearing the parts and introducing a finger, $I$ felt, as $I$ expected, the detached and dislocated head of the femur, and removed it. The thigh-bone being now projected through the wound, a portion of it, all that was seen to be denuded and diseased, was removed. On a further examination, however, of the shaft of the bone, it became evident that any effurt to save the limb would be fruitless, and I determined at once on its removal.

Two difficulties now met me. In the first place, I had only two assistants, and the patient was so anæmic and prostrate that the slightest loss of blood would at once be fatal; and, in the second place, the posterior flap had been spoilt by the previous incisions, and the patient was such a skeleton that it was no easy matter to discover tissue sufficient to form a respectable stump from.

The first difficulty was obviated by placing an abdominal tourniquet over the aorta; and the second, by ignoring the first incision and suturing it partly up afterwards. So complete was the stoppage of the circulation through the aorta that the vessels were taken up and ligatured without the loss of a drop of blood. Before the conclusion of the operation, however, the patient apparently quietly died. All signs of animation ceased; the chest was perfectly still, and no pulse could be detected at the wrists. Thinking the pressure of the tourniquet on the abdomen might be producing an injurious effect, I at once removed it, and with the aid of mechanical and stimulative assistance suspended animation was slowly restored.

For the following notes of the case I am indebted to $\mathrm{Dr}$. Robertson, to whose care and attention the recovery of the patient is greatly due.

First day after operation.-Pulse feeble and rapid; mach thirst, and little sleep.

Second day.-Pulse 120, stronger; slept better ; takes food well. Stump healthy.

Third day.-Pulse 130 ; bowels loose, and ejected matter very offensive; had a moderately good night. Stump commencing to discharge.

Fourth day.-Pulse 140 ; fererish, and little sleep.

Fifth day.-Pulse 135; skin hot. One of the ligatures came away. 